\title{
Data Science Curriculum in Library Information Science for School Librarians
}

\author{
Ji Hei Kang \\ Dongduk Women's University \\ 60, Hwarang-ro 13-gil, Seongbuk-gu, Seoul, Korea \\ Republic of Korea \\ jhkang@dongduk.ac.kr
}

\begin{abstract}
As a generation of students known as "digital natives" adopts new technology, schools are embracing the same technologies in the classroom. More than ever, teachers are applying technology to problem solving and decision making, and new methods for evaluation are replacing traditional rote learning and assessment. The new methods, however, are also producing vast amounts of data that need to be understood and applied effectively - a task falling, increasingly, to the school librarian because he or she is already familiar with cataloguing and retrieving information. Because of the need to manage information on a different scale, the proposed poster illustrates how we should teach data usage to school librarians.

Currently, there are five categories of data science courses that iSchools teach (Si, Zhuang, Xing and Guo, 2013): (1) research methods, (2) data science, data management, and data service, (3) data statistics and analysis, (4) data warehouse, and (5) information studies and technologies. The proposed poster will summarize these areas, perhaps as follows:

- Research method courses provide school librarians with the skill-set needed for developing courses, analyzing library user-needs, and for data collection.

- Data science, data management, and data service courses teach librarians how to manage the data sets that teachers use for teaching assignments.

- Data statistics and analysis courses help teachers and librarians to evaluate student records, analyze individual learning styles, and match student abilities with future majors.

- Data warehouse knowledge covers the storage and retrieval of new storage media, traditional information systems, and document management.
\end{abstract}


- Information studies and technology skills will promote health and financial informatics.

Although data science is still at an early stage of adoption by most school boards, the author hopes that the poster stimulates an interest in its application in K-12 schools.

Keywords: data science, curriculum, school librarians

\section{References}

Li, S., Xiaozhe, Z., Wenming, X., \& Weining, G. (2013). The cultivation of scientific data specialists: Development of LIS education oriented to e-science service requirements. Library Hi Tech, 31(4), 700-724. doi:10.1108/LHT-06-2013-0070

\section{Biographical note}

Ji Hei Kang has been working as an assistant professor at Dongduk Women's University in Seoul, South Korea.

The main topic that she focuses on is school librarians' leadership role in implementing technological innovations. For her dissertation project, she conducted research concerning school librarians' Stages of Concern in employing digital textbooks. She plans to follow up her research by applying a qualitative method to identify school librarians' Level of Use of digital textbooks. She is also interested in studying how librarians promote new types of educational technology, such as mobile augmented reality and big data. She can be contacted at jhkang@dongduk.ac.kr. 